\title{
Good intentions getting out of hand - is there a future for health care guidelines?
}

\author{
Louise HK Blume ${ }^{1,2}$ \\ Nico JHW van Weert ${ }^{3}$ \\ Jamiu O Busari ${ }^{1,4}$ \\ Diana MJ Delnoij ${ }^{2,5}$
}

'Zuyderland Medical Center, Heerlen, ${ }^{2}$ Tilburg School of Social and Behavioural Sciences, Tranzo, Scientific Centre for Transformation in Care and Welfare, Tilburg University, Tilburg, ${ }^{3} \mathrm{Q}$ ! B.V., Nijmegen, ${ }^{4}$ Department of Educational Development and Research, Faculty of Health, Medicine and Life Sciences, University of Maastricht, Maastricht, ${ }^{5}$ National Health Care Institute, Zorginstituut Nederland, Diemen, the Netherlands
Correspondence: Louise HK Blume Zuyderland Medisch Centrum, Henri Dunantstraat 5, 6419 PC Heerlen, the Netherlands

Tel +3I 455766543

Email I.blume@zuyderland.nl
This article was published in the following Dove Press journal:

Risk Management and Healthcare Policy

II May 2017

Number of times this article has been viewed

\begin{abstract}
To date, the focus of research on guidelines has been directed toward professionals, and hospitals have merely served as the context. Little research has been performed on the dilemmas of guideline adherence in hospitals, as a setting in which multiple professional guidelines have to be implemented simultaneously; also, it is still unclear which clinical guidelines have to be aligned with other external demands, such as rules, regulations, standards, indicators, norms, and so on. Hence, different ways of studying the issue of guideline implementation are called for. Keywords: guideline, implementation, development, standardization, hospital, adherence, compliance, external demands, requirements, regulations
\end{abstract}

\section{Introduction}

In the 1990s, guidelines were introduced in health care delivery as a tool that could bring state-of-the-art scientific evidence to professionals who were no longer able to keep up with the ever-growing amount of applicable evidence in the scientific literature. Clinical practice guidelines were defined as "systematically developed statements to assist practitioner and patient decisions about appropriate health care for specific clinical circumstances." "The recommendations in the guidelines were expected to improve the decision-making process between clinicians and patients, ${ }^{2}$ thereby making the task of evidence-based decision making much easier. Evidence-based medicine had its successes, as it has improved the quality of care received by patients. ${ }^{2}$ However, in recent years, researchers have become increasingly interested in the failure of guideline implementation. For example, Banja ${ }^{3}$ found that deviant practices in health care were standard. Evidence-based medicine was also described as a movement in crisis. ${ }^{4}$ Systematic reviews, research, and opinion papers in the literature that attempted to explain the reasons behind the non-compliance of guidelines revealed some explanations for this. ${ }^{5-10}$ These included implementation issues related to the characteristics of 1) the guideline themselves (eg, reliability, trustworthiness, validity $\left.{ }^{11}\right)$; 2) those who apply them (eg, professionals, nurses, chemists, etc.); 3 ) the patients they concern (eg, problems with adherence in case of multimorbidity); and 4) the context in which they are being applied (eg, hospitals, other institutions). To date, the focus of research on guideline implementation has been on the first three characteristics and less about the last characteristic, that is, context. ${ }^{10}$ This lopsided focus on the research has turned out to be a problem as the application of most guidelines occurs within the context of an institution.

Furthermore, professionals have mostly been the unit of analysis for implementation studies and the institutions - when considered - have merely been the context. Little 
research has been performed on the dilemmas of guideline adherence in hospitals, as a setting in which multiple professional guidelines must be implemented simultaneously, and in which clinical guidelines have to be aligned with other external demands, such as rules, regulations, standards, indicators, norms, and so on. Guidelines and evidence from scientific research are used and combined with policy, and enforcement organizations base their decisions on guidelines. ${ }^{12,13}$ In contrast to the supportive function guidelines are intended for, they are also used as enforcement tools in the Netherlands. ${ }^{14}$ Furthermore, the target groups subject to this enforcement process have been expanded to include hospital board of directors, as they are explicitly responsible for monitoring the adherence to guidelines. ${ }^{15}$ It is given that in many local and national health care organizations, several guidelines exists that have been found to be changing at a very fast pace, thereby creating increased uncertainties as to what to adhere to in clinical practice. ${ }^{16}$ Therefore, it was assumed that focused exploration of these dilemmas could reveal previously unnoticed challenges within the health care delivery process.

Guideline development, guideline adherence or behavior change by professionals was not investigated, as this has already been the focus of various studies in the literature, ${ }^{17}$ instead, the authors decided to conduct a series of studies to identify the problems with the implementation of guidelines from the hospitals' perspective. ${ }^{18,19}$ Some dilemmas emerged during this process, which are discussed in this perspective paper.

\section{Dilemma I - Centralized versus decentralized development}

If scientific evidence is to be used in practice, the adoption of guidelines in hospitals is essential. To achieve this, guidelines need to be disseminated structurally, so that hospitals are aware of them. It was emphasized that hospitals need to be aware, as the board is in charge of the compliance management. A hospital cannot comply with a guideline that the hospital management or professional staff does not know. ${ }^{18}$ Moreover, members of the organization should be able to accept the guidelines as trustworthy and helpful. In countries like the United States, Belgium, and the Netherlands, guidelines are developed, prepared, and disseminated by various developers and professionals and not by a centralized body, such as a central government agency. ${ }^{8}$

This decentralized development and dissemination, in which professional groups are in the lead, increases the chances of support and awareness by professionals for the guidelines that were developed and authorized by peers.
While the efficient dissemination of guidelines can enhance adherence to recommendations, developers of guidelines in many countries have failed to agree on the standardized, streamlined development of guidelines as well as in the process of their authorization and dissemination. ${ }^{20}$ If structured development and dissemination are missing, it becomes difficult for hospitals to know which guidelines to adhere to, leaving many hospital boards with a "lack of control."21 In other words, decentralized development may increase acceptance but hamper awareness.

\section{Dilemma 2 - Disease-specific guidelines versus standardization of hospital care}

The use of standardized medical decision making should be increased within hospitals to reduce preventable harm. ${ }^{6}$ To prevent undesirable practice (it may harm patients), Dutch hospital boards of directors are responsible for the adoption and correct implementation of all quality standards within a hospital. ${ }^{19}$ As most guidelines are not harmonized at a national level, many hospitals are obliged first to solve any disagreeing requirements, before deriving standardized hospital protocols. ${ }^{19}$ However, recommendations in guidelines are often disease specific and, therefore, differ between professional groups treating different types of patients within one institutional setting. Also, when applying guideline recommendations, it is essential to consider patient values and preferences along with staff experience and expertise. ${ }^{22}$ If hospital boards are not able to oversee all guidelines and patient preferences, then they cannot be responsible for the standardization of care. ${ }^{19}$ In other words, guidelines facilitate the disease-specific standardization of care but could hamper standardization on the hospital level and if used rigidly hinder the individual response of hospitals to patients.

\section{Dilemma 3 - Optimal care versus affordable care}

Professionals in guideline committees define what they see as optimal care for a given group of patients, based on scientific evidence, professional expertise, patients' preferences, and experiences, by describing recommendations for daily practices in guidelines. By using these guidelines, hospital professionals focus on the individual patient and do not necessarily take the best outcome for all (hospital) patients into account. This process is referred to as a "deontological" enterprise. ${ }^{23}$ However, in the "real world," hospital boards and managers often need to make choices. ${ }^{21}$ These may be at odds with the optimal care described by a guideline committee. 
For hospitals to improve the value of care and reduce waste, they have the responsibility to balance the delivery of care as outlined in the guidelines against the available resources in their organization. ${ }^{24}$ This process of using finite resources in the best possible way is called utilitarian enterprise. ${ }^{24}$ In essence, guidelines are often developed from a deontological point of view, without taking into account that they have to be implemented in a "utilitarian" framework. Guideline developers should not neglect this rationality, but facilitate it by grading the relative relevance of the recommendations.

\section{Dilemma 4 - Guidance versus control}

Guidelines should be seen as a reference tool to aid patient care. ${ }^{22}$ However, they are increasingly (being) used as reference standards for internal and external clinical audits, for pay for performance schemes, to negotiations with insurers, by the media and for medical lawsuits. ${ }^{7}$ Guidelines that were designed with the intention of keeping the knowledge of professionals concise and up to date are being used for broader purposes, for example, for control interests and enforcement measures. The question that arises, as a result, is how the original intention relates to the current and contemporary application in the field. For instance, Dutch hospital managers question whether the guidelines that are enforced by regulators are also the ones that reduce the most risk or contribute the most to quality improvement in a hospital. ${ }^{21}$ Hospitals differ in their strengths and weaknesses, and in the populations that they serve and therefore in the risks manifested in patient care. As described earlier, hospitals need a certain degree of autonomy to make choices that reflect the needs of their particular patient population and region. They need to be able to focus on specific topics that need quality improvement for which guidelines can offer valuable support. External control mechanisms, however, force hospitals to concentrate on some guidelines at the expense of other topics, which leads to a misfit between internal and external demands. ${ }^{21}$ In other words, control should help hospitals to proactively focus on quality issues that need the most attention in their case.

\section{Synthesis}

Hospitals are vital stakeholders in the development and use of guidelines. One cannot exist without the other. Nonetheless, many hospitals worldwide struggle with the implementation of guidelines., ${ }^{4,25}$ To deal with the implementation struggle as described in dilemma 1 and dilemma 2, improvements in the process of developing and disseminating clinical guidance were proposed. Also, a new approach that is not only practical but also calls for a different approach is being looked for. First, it is important that representatives of hospitals are involved in the development process in the case of guidelines that (are expected to) make recommendations that have a profound impact on hospital budgets. For making the recommendations, the GRADE (Grading of Recommendations Assessment, Development and Evaluation) working group recommends two steps. The first is to consider whether the use of resources is important (or critical). The second step is to analyze the potential impact of the specific items of resource use on different strategies. They argue that in order to consider all the relevant resources and costs, "it is important that guideline developers include the relevant stakeholders and not just clinicians". ${ }^{26}$ Second, guideline developers should develop and use formats, for example, consisting of a standardized set of modules or building blocks, to enable users to compare recommendations across disease-specific guidelines quickly. Furthermore, in countries with decentralized development, some form of centralized dissemination would ease the burden on individual hospitals and other frequent users of guidelines. Improving recommendations and dissemination could enhance the guideline implementation in practice. So, practical adaptions that could certainly simplify matters for hospital boards and professionals are summarized in Box 1.

However, the problem cannot be solved by a better organization and management of guideline development only. It was suggested that the ultimate goal is not guideline implementation and compliance. The authors are looking for a new way out that is not only practical but also calls for a different approach to be able to address dilemma 3 and dilemma 4. As stated in the "Introduction," the original purpose of guidelines was to improve quality by making

\section{Box I Recommendations}

Practical:

- Involve hospitals in guideline development (dilemma 2)

- Use standardized sets of modules for guideline development (dilemma 3)

- Aim for centralized dissemination (dilemma I)

Conceptual:

- Use guidelines for formative assessment mainly (dilemma 4)

- Accommodate summative assessment in limited priority areas based on risks for patients as assessed by guideline developers (dilemma 3 and dilemma 4)

Research:

- Choose the hospital as the unit of analysis when studying the implementation of clinical guidelines (dilemma 2) 


\section{Centralized}

dissemination

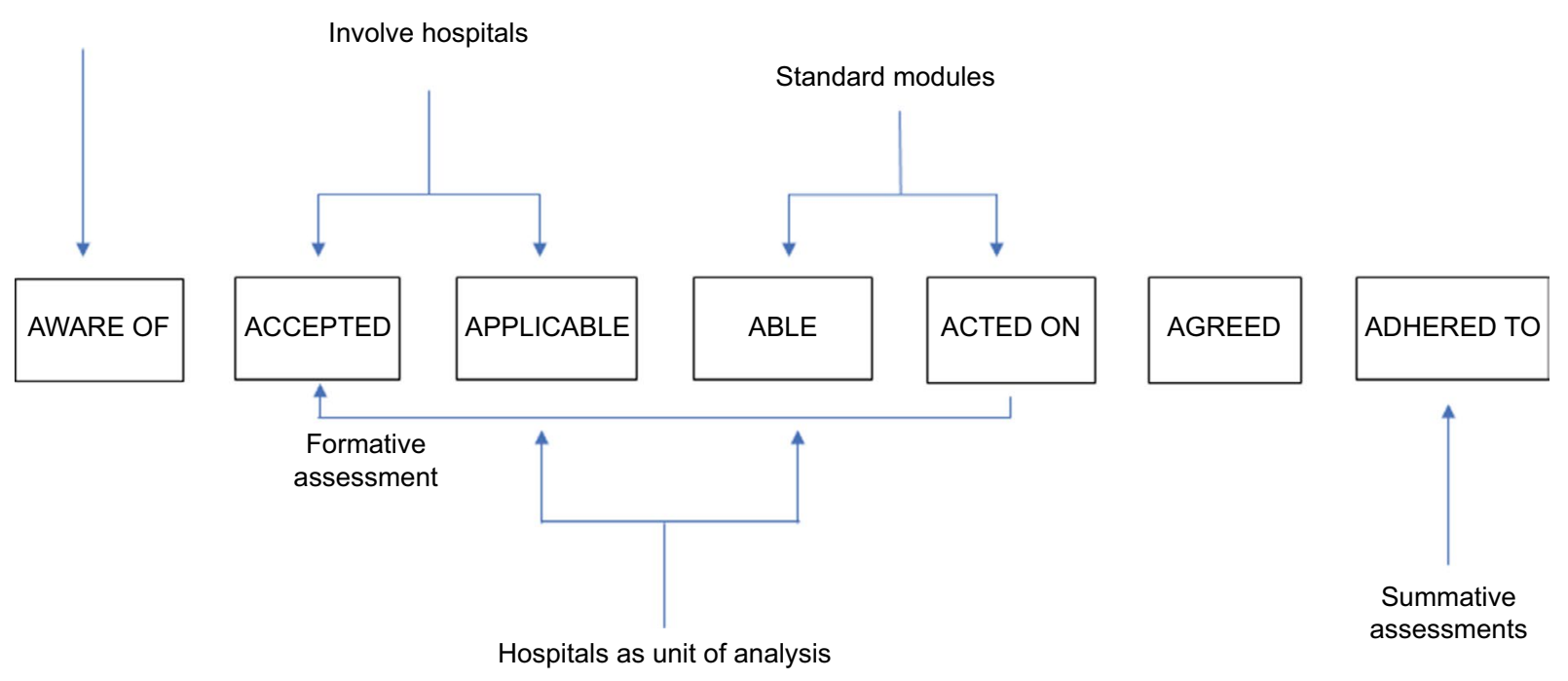

Figure I A process outline.

the evidence-based choice the easier choice. To accomplish this, an evolution return to a model in which guidelines are essentially used for learning (formative assessments) instead of control, rewards, and punishments (summative assessments) is advocated. The aim is to help to identify the strength and weaknesses of a hospital. This learning can create space for hospitals to determine together with their patients and professionals which improvements are needed. Using evidence, and therefore guidelines, helps to choose wisely. Shifting the focus to the learning capacity of hospitals and professionals may have a more favorable impact on health care quality than increased control using summative assessments. However, some limited forms of summative assessments may still be necessary for specific safety aspects. Guideline developers could help guideline users identify those aspects by clearly indicating which recommendations should be seen as mandatory and motivate this by an assessment of the risks involved with non-compliance. The authors added the recommendations presented in Box 1 to simplify matters for hospital boards and professionals to the leaky evidence pipeline (Figure 1). ${ }^{27}$ The recommendations can minimize the leaks that occur between the seven stakes of the pipeline.

Finally, the authors call for different ways of studying the issue of guideline implementation. To date, research is about guidelines for professionals, and hospitals are merely the context. The emphasis should be on the cohesion between hospitals and the health professionals. It was advised that the hospital is the starting point instead of just the context of research. It should be the unit of analysis.

\section{Disclosure}

NJHWW is leading the development of a consultancy program on hospital governance for Q! B.V., in which he holds a minority share. This study and salary for the first author were funded by Zuyderland Medical Centre and the Dutch Hospital Association (NVZ). The other authors report no conflicts of interest in this work.

\section{References}

1. Field MJ, Lohr KN, editors. Guidelines for Clinical Practice: from Development to Use. Washington, DC: National Academy Press; 1992.

2. Institute of Medicine (US) Committee on Standards for Developing Trustworthy Clinical Practice Guidelines; Graham R. Clinical Practice Guidelines We Can Trust. Washington, DC: National Academies Press; 2011.

3. Banja J. The normalization of deviance in healthcare delivery. Bus Horiz. Tab 2010;53:139-148.

4. Greenhalgh T, Howick J, Maskrey N. Evidence based medicine: a movement in crisis? BMJ. 2014;348:g3725.

5. Lugtenberg M, Zegers-van Schaick JM, Westert GP, Burgers JS. Why don't physicians adhere to guideline recommendations in practice? An analysis of barriers among Dutch general practitioners. Implement Sci. 2009;4:54.

6. Pronovost PJ. Enhancing physicians' use of clinical guidelines. JAMA. 2013;310(23):2501-2502.

7. Scott IA, Guyatt GH. Suggestions for improving guideline utility and trustworthiness. Evid Based Med. 2013;19:41-46.

8. Shekelle P, Aronson MD. Clinical practice guidelines; 2015. Available from: https://www.uptodate.com/contents/overview-of-clinicalpractice-guidelines. Accessed November 18, 2015.

9. Ruan X, Ma L, Vo N, Chiravuri S. Clinical practice guidelines: the more, the better? NAm J Med Sci (Boston). 2015;8(2):77-80.

10. Cabana MD, Rand CS, Powe NR, et al. Why don't physicians follow clinical practice guidelines? A framework for improvement $\mathrm{J} \mathrm{Am} \mathrm{Med}$ Assoc. 1999;282(15):1458-1465.

11. Shekelle PG, Ortiz E, Rhodes S, et al. Validity of the Agency for Healthcare Research and Quality clinical practice guidelines: how quickly do guidelines become outdated? JAMA. 2001;286:1461-1467. 
12. Lavis JN, Røttingen JA, Bosch-Capblanch X, et al. Guidance for evidence-informed policies about health systems: linking guidance development to policy development. PLoS Med. 2012;9:e1001186.

13. Paprica PA, Culyer AJ, Elshaug AG, Peffer J, Sandoval GA. From talk to action: policy stakeholders, appropriateness, and selective disinvestment. Int J Technol Assess Health Care. 2015;31(4):236-240.

14. Health Care Inspectorate (IGZ). Available from: https:/www.igz.nl/ english/about-us/enforcement_measures/.Accessed February 24, 2017.

15. Brancheorganisaties Zorg. Zorgbrede Governance Code; 2009. Available from: https://www.brancheorganisatieszorg.nl/wp-content/ uploads/2010/01/Zorgbrede-Governancecode-2010-.pdf.pdf. Accessed January 2, 2017.

16. Leistikow I, Mulder S, Vesseur J, Robben P. Learning from incidents in healthcare: the journey, not the arrival, matters. BMJ Qual Saf. 2017;26(3):252-256.

17. Solberg L. Guideline implementations: what the literature doesn't tell us. Jt Comm J Qual Improv. 2000;26:525-537.

18. Blume LHK, van Weert NJHW, Delnoij DMJ. How to manage external demands in hospitals - the case of atrium MC. Healthcare. 2015;3(3):157.

19. Blume LHK, Weert NJHWV, Busari JO. Guideline adherence: how do boards of directors deal with it? A survey in Dutch hospitals. $J$ Hosp Adm. 2016;5(5):21.
20. Maarse J, Ruwaard D, Spreeuwenberg C. The governance of quality management in Dutch health care: new developments and strategic challenges. Qual Manag Health Care. 2013;22(3):236-247.

21. Blume LHK, Weert NJHWV, Busari JO, et al. Optimal use of external demands in hospitals - a Delphi study from the Netherlands. $B M C$ Health Serv Res. 2016;16(1):1-9.

22. Jevsevar D, Bozic K. Orthopaedic healthcare worldwide: using clinical practice guidelines in clinical decision making. Clin Orthop Relat Res. 2015;473(9):1-3.

23. Garbutt G, Davies P. Should the practice of medicine be a deontological or utilitarian enterprise? J Med Ethics. 2011;37:267-270.

24. Elshaug AG, Rosenthal MB, Lavis JN, et al. Levers for addressing medical underuse and overuse: achieving high-value health care. Lancet. 2017;pii:S0140-6736.

25. Hisham R, Ng CJ, Liew SM, Hamzah N, Ho GJ. Why is there variation in the practice of evidence-based medicine in primary care? A qualitative study. BMJ Open. 2016;6:e010565.

26. Brunetti M, Shemilt I, Pregno S, et al. GRADE guidelines: 10. Considering resource use and rating the quality of economic evidence. J Clin Epidemiol. 2013;66:140-150.

27. Glasziou P, Haynes B. The paths from research to improved health outcomes. ACP J Club. 2005;142:A8-A10.
Risk Management and Healthcare Policy

\section{Publish your work in this journal}

Risk Management and Healthcare Policy is an international, peer-reviewed open access journal focusing on all aspects of public health, policy, and preventative measures to promote good health and improve morbidity and mortality in the population. The journal welcomes submitted papers covering original research, basic science, clinical and epidemiological

\section{Dovepress}

studies, reviews and evaluations, guidelines, expert opinion and commentary, case reports and extended reports. The manuscript management system is completely online and includes a very quick and fair peerreview system, which is all easy to use. Visit http://www.dovepress.com/ testimonials.php to read real quotes from published authors.

Submit your manuscript here: https://www.dovepress.com/risk-management-and-healthcare-policy-journal 